\title{
Shifts in bacterial community composition in the rumen of lactating dairy cows under milk fat-depressing conditions ${ }^{1}$
}

\author{
P. J. Weimer, ${ }^{*} \dagger^{2}$ D. M. Stevenson, ${ }^{*}$ and D. R. Mertens ${ }^{*}$ \\ *USDA-ARS, US Dairy Forage Research Center, Madison, WI 53706 \\ †Department of Bacteriology, University of Wisconsin-Madison, 53706
}

\begin{abstract}
Eighteen ruminally cannulated dairy cattle were fed a series of diets (in 28-d periods) designed to elicit different degrees of milk fat depression (MFD) for the purpose of relating MFD to ruminal bacterial populations. Cows were fed a TMR containing $25 \%$ starch (DM basis) supplied as corn silage, a slowly fermented starch (SFS treatment, period 1), then switched to a TMR containing $27 \%$ starch, much of it supplied as ground high-moisture corn, a rapidly fermented starch (RFS treatment, period 2). In period 3, the RFS diet was amended with $13.6 \mathrm{mg}$ of monensin $/ \mathrm{kg}$ of $\mathrm{DM}$ (RFS/Mon treatment), and in period 4, the cows were returned to the RFS diet without monensin (RFS/Post treatment). Effect of both starch source and monensin on milk fat percentage varied by cow, and cluster analysis identified 4 pairs of cows having distinct milk fat patterns. Archived ruminal liquors and solids from the 4 pairs were processed to isolate bacterial DNA, which was subjected to automated ribosomal intergenic spacer analysis followed by correspondence analysis to visualize bacterial community composition (BCC). One pair of cows (S-responsive) showed MFD on RFS feeding, but displayed no additional MFD upon monensin feeding and a fat rebound upon monensin withdrawal. The second pair of cows (M-responsive) showed no MFD upon switch from the SFS diet to the RFS diet, but displayed strong MFD upon monensin feeding and no recovery after monensin withdrawal. Both groups displayed major shifts in BCC upon dietary shifts, including dietary shifts that both did and did not change milk fat production. The third pair of cows (SM-responsive) displayed reduction of milk fat on both RFS and RFS/ Mon diets, and fat returned to the levels on the RFS diet upon monensin withdrawal; these cows showed a more gradual shift in BCC in response to both starch source

\footnotetext{
Received March 12, 2009.

Accepted October 19, 2009

${ }^{1}$ Mention of specific products is for informational purposes and does

${ }^{2}$ Corresponding author: Paul.Weimer@ars.usda.gov
} not constitute an endorsement or warranty over other products not mentioned.
\end{abstract}

and monensin. The fourth pair of cows (nonresponsive) did not display changes in milk fat percentage with dietary treatment and showed only minor shifts in BCC with dietary treatment. Regardless of milk fat response, $\mathrm{BCC}$ did not reassemble its original state upon monensin withdrawal, though the difference was strongest in M-responsive cows. One amplicon length (representing a single bacterial species) was elevated in most, but not all, MFD-susceptible (S-, M-, or SM-responsive) cows relative to milk fat-nonresponsive cows, whereas 2 amplicon lengths displayed reduced abundance under MFD conditions. Overall, this study demonstrates an association between MFD and wholesale shifts of microbial communities in the rumen.

Key words: bacterial community composition, milk fat depression, monensin, rumen

\section{INTRODUCTION}

Because of the strong influence of milk fat on milk pricing, milk fat depression (MFD, defined as the reduction in the percentage or yield of milk fat) is a serious economic problem for dairy producers. Modern dairy diets containing high concentrations of highly digestible cereal grains are widely used to maximize milk production, but such diets often induce MFD (Emery, 1988; Peterson et al., 2003; Nielsen et al., 2006). The problem can be exacerbated further in some cows by certain feed additives, such as monensin, that are known to promote changes in ruminal microbial populations (Van Beukelen et al., 1984; Ramanzin et al., 1997; Oelker et al., 2009). Elucidating the mechanism underlying MFD thus has been of longstanding interest to dairy nutritionists. Evidence accumulated over the past decade has focused attention on certain long-chain unsaturated fatty acids as proximal regulators of mammary lipogenesis (Bauman and Griinari, 2003). These long-chain unsaturated fatty acids can be produced or modified by some members of the ruminal microbiota, for example, through biohydrogenation reactions (Harfoot and Hazlewood, 1988; Wallace, 2008). Consequently, induction of MFD may result from alteration of the populations or activities of particular 
microbial species involved in these reactions; however, it has been difficult to assign the production or conversion of these acids to specific ruminal microbes. Maia et al. (2007) reported that trans-10,cis-12 conjugated linoleic acid (t10c12-CLA), the long-chain unsaturated fatty acid most closely associated with MFD (Bauman and Griinari, 2003), was not produced by any of $23 \mathrm{ru}-$ minal bacterial species tested in pure culture. Ruminal metabolism of long-chain unsaturated fatty acids is also poorly understood. Butyrivibrio fibrisolvens (Rosenfeld and Tove, 1971) is perhaps the best-characterized of the biohydrogenating bacteria, and Boeckaert et al. (2008) demonstrated that accumulation of trans- $\mathrm{C}_{18: 1}$ fatty acids in the rumen is associated with changes in the relative population sizes of certain strains of Butyrivibrio, although they did not examine milk fat response in their study. However, the importance of B. fibrisolvens in biohydrogenation reactions in the rumen is unclear because this species typically displays very low ruminal abundance even when quantified by sensitive molecular methods (Forster et al., 1997; Stevenson and Weimer, 2007; Weimer et al., 2008).

Anecdotal evidence suggests that diets containing both highly fermentable starch [e.g., high-moisture corn (HMC)] and monensin increase the incidence of MFD. Recent evidence using quantitative real-time PCR (qPCR) with relative quantification indicated that monensin decreased the relative abundance of several bacterial species, including B. fibrisolvens and Megasphaera elsdenii, although their abundance, even in the absence of monensin, was very small $(<0.01 \%$ of total bacterial $16 \mathrm{~S}$ rRNA gene copies, a measure of population abundance; Weimer et al., 2008). Moreover, that study revealed that the contributions by most of the 16 taxa examined to total $16 \mathrm{~S}$ rRNA gene copies were unaffected by monensin. Evaluation of clone libraries constructed from 16S rRNA genes obtained from bulk ruminal DNA have revealed that most (perhaps $90 \%$ or more) ruminal bacteria show $<97 \%$ sequence identity to cultivated species (Whitford et al., 1998; Tajima et al., 1999, 2000), suggesting that these unidentified strains represent novel species that have to date resisted cultivation (Wallace, 2008). Moreover, qPCR studies have shown that the 13 most commonly studied ruminal bacterial species contribute $<7 \%$ of the total $16 \mathrm{~S}$ rRNA gene copies in ruminal contents (Stevenson and Weimer, 2007). It is thus highly likely that a substantial number of currently uncultured species may respond to the presence of feed additives like monensin, and that at least some of these species may be directly involved in the production or consumption of the long-chain unsaturated fatty acids that regulate milk fat synthesis or may affect populations of other species that may be more directly involved. During the past decade, sev- eral methods based on amplification and quantitation of taxon-specific segments of genomic DNA have been developed for profiling entire bacterial communities (Fisher and Triplett, 1999; Giraffa and Neviani, 2001; Danovaro et al., 2006; Loisel et al., 2006). We used one such community fingerprinting technique, automated ribosomal intergenic spacer analysis (ARISA), to examine the effect of starch fermentability and the feeding and withdrawal of monensin on ruminal bacterial community composition (BCC) in lactating dairy cows that displayed different patterns of MFD.

\section{MATERIALS AND METHODS}

\section{Experimental Design}

The experiment was designed to determine differential effect of monensin feeding and withdrawal on milk fat production under conditions of high starch fermentability and to relate any differential milk fat response among cows to the population structure of the ruminal bacterial community. Specifically, we sought to identify internally coherent groups of cows that differed, or did not differ, in milk fat production in response to starch fermentability, or monensin, or both, for post-hoc examination of bacterial populations in archived ruminal contents. This strategy permitted reducing the total number of samples that required the labor-intensive process of purifying bulk ruminal DNA from a very large sample set.

Experiments were performed in accordance with a research protocol approved by the University of Wisconsin-Madison's Research Animal Resource Center. Eighteen lactating, ruminally cannulated Holstein cows (7 primiparous, 11 multiparous; mean $\mathrm{BW}=599 \mathrm{~kg}$, DIM $=50-134$, milk yield $=30-52 \mathrm{~kg} / \mathrm{d}$ ) that had never received monensin were maintained in adjacent tie-stalls at the US Dairy Forage Research Center farm near Prairie du Sac, Wisconsin. Cows were fed the TMR once daily at approximately $0830 \mathrm{~h}$, had continuous access to water, and were milked twice daily. Refusals were collected and weighed before each feeding, and a handful of refusals from individual cows were collected just before feeding on each of the last $7 \mathrm{~d}$ of each period (as defined later); these samples were composited by cow and stored frozen before compositional analysis.

The 2 primary sources of starch for the diets were corn silage and HMC, known to differ greatly in ruminal fermentability (Owens et al., 1986). Both were ensiled in tower silos for $>200 \mathrm{~d}$ before the start of the experiment. The corn silage was ensiled with minimal kernel processing (cracking of the grain). The HMC was finely ground (Clay Hammer Mill, Cedar Falls, IA) each day during removal from the silo to decrease 
Table 1. Nutritional composition of dietary treatments used in this study ${ }^{1}$

\begin{tabular}{lcccc}
\hline Item, ${ }^{2} \%$ DM in diet & SFS & RFS & RFS/Mon & RFS/Post \\
\hline Ingredient & & & & \\
Alfalfa haylage & 17.3 & 14.4 & 17.5 & 16.6 \\
Corn silage & 59.8 & 46.4 & 42.8 & 37.7 \\
High-moisture corn (fine-ground) & - & 13.1 & 13.6 & 18.4 \\
Soybean meal & 2.4 & 5.6 & 5.4 & 7.4 \\
Roasted soybeans (rolled) & 8.8 & 8.8 & 8.8 & 8.8 \\
Distillers grains & 5.7 & 5.7 & 5.7 & 5.7 \\
Wheat middlings & 4.5 & 4.5 & 4.5 & 4.5 \\
CaCO & 0.24 & 0.24 & 0.24 & 0.24 \\
Blood meal (bovine) & 0.13 & 0.13 & 0.13 & 0.13 \\
DynaMate & 0.08 & 0.08 & 0.08 & 0.08 \\
NaHCO & 0.59 & 0.59 & 0.59 & 0.59 \\
Vitamin and mineral mix & 0.24 & 0.24 & 0.24 & 0.24 \\
Iodized NaCl & 0.24 & 0.24 & 0.24 & 0.24 \\
Monensin & - & - & 0.00136 & - \\
Component & & & & 32.1 \\
aNDF & 33.0 & 31.9 & 32.1 & 40.3 \\
NFC & 40.8 & 40.2 & 39.9 & 17.8 \\
Starch & 24.4 & 28.0 & 26.9 & 5.2 \\
CP & 17.5 & 17.8 & 17.4 & 5.8 \\
Ether extract & 4.7 & 4.8 & 5.0 & 5.5 \\
Ash & 6.3 & 6.0 & 5.5 & \\
\hline
\end{tabular}

${ }^{1}$ Dietary treatments, applied in indicated order: SFS $=$ TMR containing slowly fermented starch source (corn silage); RFS = TMR containing more rapidly fermentable starch (ground high-moisture corn in addition to corn silage); RFS/Mon = RFS supplemented with monensin; RFS/Post = RFS following monensin withdrawal.

${ }^{2}$ DynaMate manufactured by a division of IMC-Agrico (Mundelein, IL).Vitamin and mineral mix manufactured by Land O'Lakes (St. Paul, MN). Monensin (Rumensin 80, Elanco Animal Health, Greenfield, IN) added at the indicated rate with the soybean meal. aNDF $=$ NDF determined after amylase treatment (Mertens, 2002).

particle size and increase ruminal fermentability (San Emeterio et al., 2000; Oba and Allen, 2003). The specific diets (Table 1) were fed sequentially to all 18 cows over four 28-d periods because we previously observed that monensin altered some microbial populations both after feeding and after withdrawal (Weimer et al., 2008), making other experimental designs (e.g., a Latin square) problematic for microbiological studies. In period 1, the TMR contained starch provided as corn silage (diet SFS, slowly fermented starch). In period 2, the cows were switched to a TMR in which starch was provided in slightly higher concentration ( $27 \%$ of DM) and as both corn silage and HMC (diet RFS, rapidly fermented starch). This diet was introduced over a 3-d period $(67 \%$ SFS $/ 33 \%$ RFS on d $1,33 \%$ SFS $/ 67 \%$ RFS on $\mathrm{d} 2,100 \%$ RFS on $\mathrm{d} 3$ ) between periods 1 and 2 . In period 3, cows were fed the same RFS diet but it was amended with monensin (Rumensin 80, Elanco Animal Health, Greenfield, IN) at $13.6 \mathrm{mg} / \mathrm{kg}$ of DM (diet RFS/Mon). In period 4, cows were returned to the RFS diet without monensin (here denoted as RFS/ Post, to indicate the RFS diet was fed after monensin withdrawal). Throughout the trial, feed ingredients were sampled weekly for prediction of composition by near-infrared spectroscopy and the diets were reformulated to contain, on a DM basis, similar levels (31\%) of NDF analyzed after $\alpha$-amylase and sodium sulfite treatment (aNDF; Mertens, 2002), NFC (40\%), starch (25\% in period 1 and $27 \%$ in periods 2,3 , and 4 ), and CP (17.5\%). Actual component concentrations were subsequently determined by standard wet chemical analyses. Starch was determined by Cumberland Valley Analytical Services (Maugansville, MD) using the acetate buffer method with correction for free glucose as described by Hall (2009).

\section{Sampling and Analysis of Milk and Ruminal Contents}

Milk samples were collected from twice-daily milkings during the last $5 \mathrm{~d}$ of each dietary treatment period. Cows were weighed immediately after the p.m. milking on the last $2 \mathrm{~d}$ of each period. Ruminal $\mathrm{pH}$ measurements and samplings were conducted on each of the last $3 \mathrm{~d}$ of each period. The $\mathrm{pH}$ readings were taken cowside $6 \mathrm{~h}$ after feeding using a model pH340i portable digital pH meter (WTW, Weilheim, Germany). A 2-point (pH 7.00 and 4.01) calibration of the $\mathrm{pH}$ electrode was conducted immediately before ruminal sampling. Ruminal samples were withdrawn at the same time as $\mathrm{pH}$ measurement using a new arm-length disposable plastic glove for each cow. Each ruminal sample was immediately hand-squeezed through 4 layers of cheesecloth at cowside, and the solids and liquid fractions were placed in separate $50-\mathrm{mL}$ Corning polypropylene centrifuge 
tubes (Lowell, MA) and then placed in ice before freezing at $-80^{\circ} \mathrm{C}$. Sequential ruminal samplings for the set of 18 cows were typically accomplished over a period of 35 to $40 \mathrm{~min}$. To minimize systematic differences in sampling time, sampling was conducted in 3 blocks of 6 cows, with the order of sampling of blocks shifted during each of the 3 sampling days within each period.

Milk components (percentages of fat, protein, and lactose, along with milk urea N) were predicted by NIRS analysis (AgSource, Verona, WI). Ruminal VFA were determined by HPLC as described previously (Weimer et al., 1991).

\section{Statistical Analysis}

Cluster analysis was performed by analyzing mean milk fat percentage and mean milk fat yield data from individual cows during each period using Minitab software (v. 13, Minitab, State College, PA) to determine Euclidian distances in a single linkage analysis in order to group cows by milk fat response to dietary treatment. As described in the Results section, clustering resulted in 4 pairs of cows having internally consistent milk fat responses. Because this analysis was conducted in multidimensional space, the resulting cluster groups were visualized by first subjecting the data to principal component analysis in Minitab to obtain the first 4 principal components and then plotting the first 3 principal components in PSIPLOT (v. 7.01 for Windows, Poly Software International, Pearl River, NY).

\section{Microbial Population Analysis}

Once the groups of cows having milk fat response patterns of interest were identified, bulk DNA from archived ruminal samples from those cows was recovered for analysis of BCC. The liquid and solid phases of ruminal contents were processed separately. The DNA was extracted from liquid ruminal contents directly, and was extracted from cells removed from fiber (solid phase) by a sequential washing protocol using chilled buffer (Stevenson and Weimer, 2007); prior separation of cells was necessary to obtain samples of sufficient homogeneity for bead-beating at small volumetric scale. The BCC patterns in the extracted and PCR-amplified DNA samples were determined using ARISA. This method exploits the variability in the size of an internally transcribed sequence (ITS) between the $16 \mathrm{~S}$ and 23S rRNA genes among individual species of bacteria (Fisher and Triplett, 1999). The spacer region can be up to approximately 1,400 bp in length. Although the length of the spacer region varies among bacterial species, it is generally constant for an individual species, making it a useful tool for tracking both the culturable and nonculturable bacterial populations. The mixture of amplicons produced by PCR was separated by capillary electrophoresis. Electrophoretograms of DNA amplified from the ruminal samples can contain more than 200 separate peaks, with the number of peaks corresponding to the minimum number of bacterial species present in the sample (Fisher and Triplett, 1999).

Methods for ARISA described by Fisher and Triplett (1999) were modified as follows. The domain bacteriaspecific oligonucleotide primers used for ARISA were ITSF (5'-GTCGTAACAAGGTAGCCGTA-3') and ITSReub (5'-GCCAAGGCATCCAAC-3'). The primer ends were complementary to the respective positions 1423 and 1443 of the 23S rRNA and positions 38 and 23 of the 16S rRNA of Escherichia coli (Cardinale et al., 2004). This primer set was selected for use because it amplifies a larger range of spacer lengths than other primer sets (e.g., 134-1,387 bp in the study of Cardinale et al., 2004). Primers were synthesized and labeled with Beckman Coulter (Fullerton, CA) WelRed \#2 infrared fluorescent dye (Sigma-Proligo) and were reconstituted in water to a working concentration of $400 \mathrm{n} M$. Template DNA from the ruminal samples was prepared as described previously (Weimer et al., 2008). The DNA concentrations were determined spectrophotometrically and diluted to a working concentration of $10 \mu \mathrm{g} / \mathrm{mL}$. The ARISA PCR reactions were carried out in $20-\mu \mathrm{L}$ volumes using Promega (Madison, WI) GoTaq Flexi system reagents containing $4.0 \mu \mathrm{L}$ of $\mathrm{Mg}$-free buffer (5× concentrate), $2.0 \mu \mathrm{L}$ of $2.5 \mathrm{mM} \mathrm{MgCl} 2,0.5 \mu \mathrm{L}$ of $200 \mu M$ deoxynucleotide triphosphates mixture, $2.0 \mu \mathrm{L}$ each of the 2 primers, $2.0 \mu \mathrm{L}$ of template DNA, $7.0 \mu \mathrm{L}$ of nuclease-free water, and $0.5 \mu \mathrm{L}$ of Taq polymerase. Molecular biology-grade mineral oil (Sigma-Aldrich, St. Louis, MO) was added to each tube in amounts sufficient to cover the reaction mixture, and the PCR reaction was carried out in an Applied Biosystems thermocycler (Foster City, CA). The thermocycler conditions were 1 cycle of $94^{\circ} \mathrm{C}$ for $2 \mathrm{~min}$, followed by 30 cycles of $94^{\circ} \mathrm{C}$ for $30 \mathrm{~s}, 55^{\circ} \mathrm{C}$ for $60 \mathrm{~s}$, and $72^{\circ} \mathrm{C}$ for $120 \mathrm{~s}$, and finished with 1 cycle of $72^{\circ} \mathrm{C}$ for $120 \mathrm{~s}$.

Amplified PCR product was resolved in a Beckman Coulter CEQ8000 Genetic Analysis System by mixing $1.0 \mu \mathrm{L}$ of PCR product with $0.5 \mu \mathrm{L}$ of Beckman Coulter WelRed \#1 infrared fluorescent dye-labeled DNA standard ladder consisting of 23 sizes of DNA ranging from 50 to 1,000 bp (MapMarker 1000, BioVentures, Murfreesboro, TN) and $39 \mu \mathrm{L}$ of sample loading solution (Beckman Coulter). This mixture was then loaded into microtiter plates, molecular biological-grade mineral oil was added to cover the liquid surface, and the capillary electrophoresis was conducted according to the manufacturer's directions. The run parameters consisted of a capillary temperature of $50^{\circ} \mathrm{C}$, a dena- 
turation temperature of $90^{\circ} \mathrm{C}$ for $120 \mathrm{~s}$, an injection voltage of $2.0 \mathrm{kV}$ for $30 \mathrm{~s}$, and a separation voltage of $6.0 \mathrm{kV}$ for $90 \mathrm{~min}$.

The resulting data was imported as an SCF 3.0 file for analysis using GeneMarker software (v. 1.75, SoftGenetics LLC, State College, PA). Settings to detect and quantify the peaks were based on the methods for amplicon fragment length polymorphism analysis specified in the GeneMarker manual. Peak sizes, in base pairs, were determined using the internal standards as described above. Using all the data, a table of peak areas was automatically generated that represented all the identifiable peaks that were present in at least 1 of the samples within the specified amplicon length (AL). This panel was then screened manually and a few of the peaks flagged as questionable by the software were deleted if they were caused by pull-up from the dyed internal base pair size standard. The software was used to perform baseline subtraction and peak smoothing. Although GeneMarker recommends a cutoff of $1 \%$ of the global and local maxima for standard amplicon fragment length polymorphism analysis, a cutoff of $0 \%$ was selected within GeneMarker because of the high peak density observed in these samples and to prevent missing minor peaks in these complex samples. All peaks corresponding to AL of $>112$ were used for analysis. This length cutoff was selected based on the smallest possible AL expected from the primers used as determined from their position in the $16 \mathrm{~S}$ and $23 \mathrm{~S}$ rRNA genes (see Figure 1 and Table 1 of Cardinale et al., 2004), and on clear peak resolution distance from the injection peak.

The resulting peak area data were tabulated, with individual sample units (a single sample taken from an individual cow at a specific sampling) as columns and AL as rows. Peak areas were converted to relative peak areas (percentage of total peak area represented by an individual peak). Correspondence analysis was performed on this data matrix by the method of Ludwig and Reynolds (1988) using custom software written in the $\mathrm{C}$ programming language to automatically perform the calculations. Vectors for $\mathrm{pH}$, total $\mathrm{m} M$ VFA, and acetate:propionate molar ratio $(\mathbf{A}: \mathbf{P})$ were added by tabulating these values as vectors, and ordination points were calculated by the method of vector fitting per McCune and Grace (2002).

Shifts in BCC resulting from dietary changes were also evaluated for each of the 8 cows by an analysis of similarity (ANOSIM; Clarke, 1993). For each liquid- or solid-phase ARISA data set from each cow, 4 data matrices were constructed: 3 for dietary shifts (SFS $\rightarrow$ RFS, $\mathrm{RFS} \rightarrow \mathrm{RFS} / \mathrm{Mon}$, and RFS/Mon $\rightarrow$ RFS/Post) and 1 for comparison of the RFS diet before monensin addition with the RFS diet after monensin withdrawal (RFS vs.
RFS/Post). Each data matrix consisted of 188 rows (relative peak area for each AL) and 6 columns (3 daily samples for each of the 2 dietary periods being compared). The ANOSIM R-values were determined using Bray-Curtis dissimilarity rankings (Clarke, 1993). The $\mathrm{R}$-value obtained for each binary comparison was evaluated against 1,000 R-values calculated by randomizing the Bray-Curtis similarity ranking of the 6 samples in the homologous data matrix. Probability values represent the fraction of these $\mathrm{R}$-values that exceeded the $\mathrm{R}$ value obtained from the nonrandomized comparison.

To identify particular AL whose relative population sizes increased or decreased in relation to milk fat response, the percentage of total peak area represented by an individual peak for each AL was subjected to analysis in PROC MIXED of SAS (SAS Institute, 1998), with milk fat response group (identified by cluster analysis as described above), diet, ruminal contents phase (liquid or solid), and sampling day within each period as main effects and as components of interactions terms. Terms having $P>0.4$ were removed from the full model before running a reduced model. Least squares means were compared using a Bonferroni $t$-test at $P=0.10$ to reduce the likelihood of type II error.

\section{RESULTS}

\section{Milk Production and Composition}

Cluster analysis based on a combination of milk fat percentage and milk fat yield, conducted under stringent conditions (similarity level 90\%), resulted in 15 separate clusters for the 18 cows. However, relaxing the similarity level to $88.5 \%$ yielded 4 multicow groups (1 group containing 3 cows and 3 groups containing 2 cows each). To facilitate handling of samples for DNA analysis (in multiples of 8), 1 cow from the 3 -cow cluster was randomly removed from the analysis, resulting in 4 clusters of 2 cows each (Table 2). The 4 pairs included 2 primiparous and 6 multiparous cows whose DIM at the start of the trial ranged from 64 to 119. Data from these 8 cows were used to compare milk production, milk composition, and ruminal chemistry across response groups, and the archived ruminal samples were used to obtain DNA for microbial population analysis. Production data from the other 10 cows are not reported here, and ruminal samples from these cows were not analyzed.

Once the clusters were identified, milk fat percentage and milk fat yield data (Table 2) were manually examined to determine which treatment affected milk fat. One pair of cows displayed decreased milk fat upon switch from the SFS diet to the RFS diet but little change upon monensin treatment or withdrawal; these 
Table 2. Clustering ${ }^{1}$ of cows based on milk fat percentage and yield on different dietary treatments ${ }^{2}$

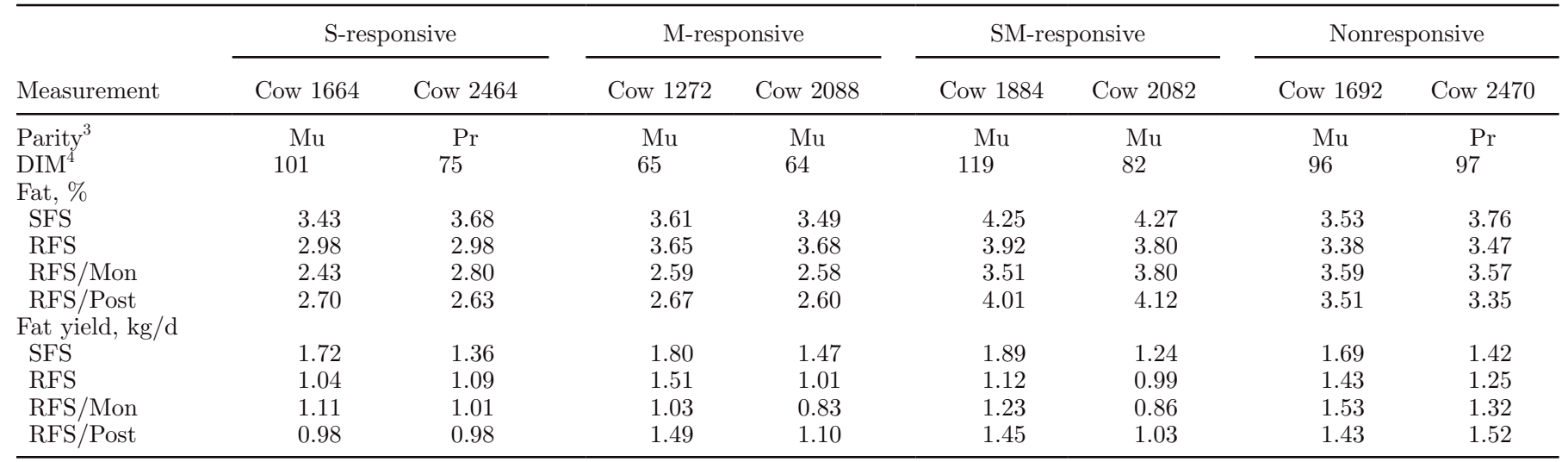

${ }^{1}$ See text for description of clustering methodology. Four response groups were identified by clustering: cows with milk fat percentage affected by starch fermentability (S-responsive), monensin (M-responsive; Rumensin 80, Elanco Animal Health, Greenfield, IN), or starch fermentability and monensin (SM-responsive), and cows not affected by either starch fermentability or monensin (nonresponsive). Euclidean distance between cluster centroids: $\mathrm{N}$ and $\mathrm{S}=1.367 ; \mathrm{N}$ and $\mathrm{M}=1.368 ; \mathrm{N}$ and $\mathrm{SM}=0.935 ; \mathrm{S}$ and $\mathrm{M}=0.686 ; \mathrm{S}$ and $\mathrm{SM}=2.077 ; \mathrm{M}$ and $\mathrm{SM}=1.938$.

${ }^{2}$ Dietary treatments, applied in indicated order: SFS $=$ TMR containing slowly fermented starch source (corn silage); RFS $=$ TMR containing more rapidly fermentable starch (ground high-moisture corn in addition to corn silage); RFS/Mon = RFS supplemented with monensin; RFS/ Post $=$ RFS following monensin withdrawal.

${ }^{3} \mathrm{Pr}=$ primiparous; $\mathrm{Mu}=$ multiparous.

${ }^{4}$ DIM at start of trial.

cows were referred to as "S-responsive." A second pair displayed no change in milk fat when switched from the SFS diet to the RFS diet along with a decrease upon monensin treatment, or an inability to recover milk fat production after monensin withdrawal, or both; these cows were referred to as "M-responsive." A third pair displayed slightly lower milk fat on the RFS and RFS/ Mon diets followed by a recovery upon monensin re- moval during feeding of the RFS/Post diet; owing to the effect of both rapidly fermented starch and monensin, these cows were referred to as "SM-responsive." A fourth pair displayed no significant changes in milk fat with any of the dietary treatments and was termed "nonresponsive." Interestingly, examination of the cluster centroids (Table 2, footnote 1 ) revealed that the milk fat response in the SM-responsive group was more

Table 3. Production and ruminal chemistry data for cows in the different milk fat response groups ${ }^{1}$

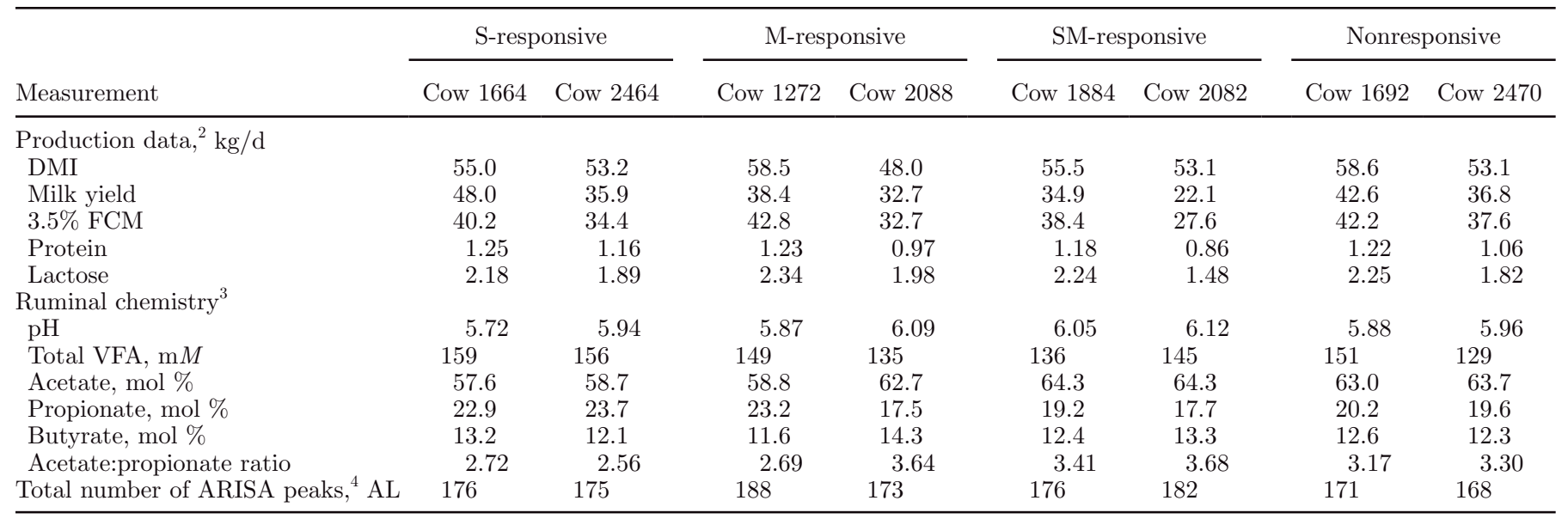

${ }^{1}$ Response groups: cows with milk fat percentage affected by starch fermentability (S-responsive), monensin (M-responsive; Rumensin 80, Elanco Animal Health, Greenfield, IN), or starch fermentability and monensin (SM-responsive), and cows not affected by either starch fermentability or monensin (nonresponsive).

${ }^{2}$ Production data from last 5 d (10 milkings) of each 28-d period, averaged across all 4 treatment periods.

${ }^{3}$ Ruminal chemistry from samples collected $6 \mathrm{~h}$ postfeeding on last $3 \mathrm{~d}$ of each 28 -d period, averaged across all 4 treatment periods.

${ }^{4} \mathrm{ARISA}=$ automated ribosomal intergenic spacer analysis; $\mathrm{AL}=$ amplicon length. Includes total number of unique AL identified in full set of 24 samples ( 3 daily samples $\times 4$ experimental periods $\times 2$ phases) for each cow. 
similar to that of the nonresponsive cows than to either the S- or M-responsive cows. The similarity between cows within a cluster is apparent in Figure 1.

Production data for the cows (Table 3) revealed substantial variation not only among cows but also between cows within each particular milk fat response group. The SCC of the milk (data not shown) ranged from 24 to $135 \times 10^{3} / \mathrm{mL}$, but did not vary among fat response groups.

\section{Ruminal Chemistry}

Cows from the 4 groups displayed similarities in $\mathrm{pH}$ and total VFA (Table 3). In accord with their slightly higher percentages of milk fat, SM-responsive cows displayed numerically higher A:P, higher molar percentages of acetate, lower molar percentages of propionate, and lower total concentrations (millimolar) of VFA than did S-responsive cows. Nonresponsive cows generally displayed numerical values between the SM-responsive cows and the S- or M-responsive cows. These data were consistent with cluster analysis results, which calculated smaller differences between centroid values for the SM- responsive and nonresponsive cows than between the SM- and either the S- or the M-responsive cows (Table 2 , footnote 1).

\section{Ruminal Bacterial Community Composition}

As is typical in ARISA (Fisher et al., 2000; Yannarell and Triplett, 2005; Kara and Shade, 2009) and other community fingerprinting studies (Felske and Osborn, 2005), an AL was considered for analysis purposes to be a DNA segment having a unique number of base pairs, identified as a unique peak upon separation of the amplicon mixture by capillary electrophoresis. The total number of AL (range $=112-708 \mathrm{bp}$ ) detected across all samples was 188 , the number of AL detected in individual samples varied from 38 to 137 (mean = 92 ), and the number of AL detected across all samples for individual cows was 168 to 188 (Table 3). As in other ARISA studies, some AL undoubtedly represented more than a single bacterial species. Thus, the number of peaks represented the minimum number of species detectable in a sample under the amplification and detection conditions used. The number of peaks obtained

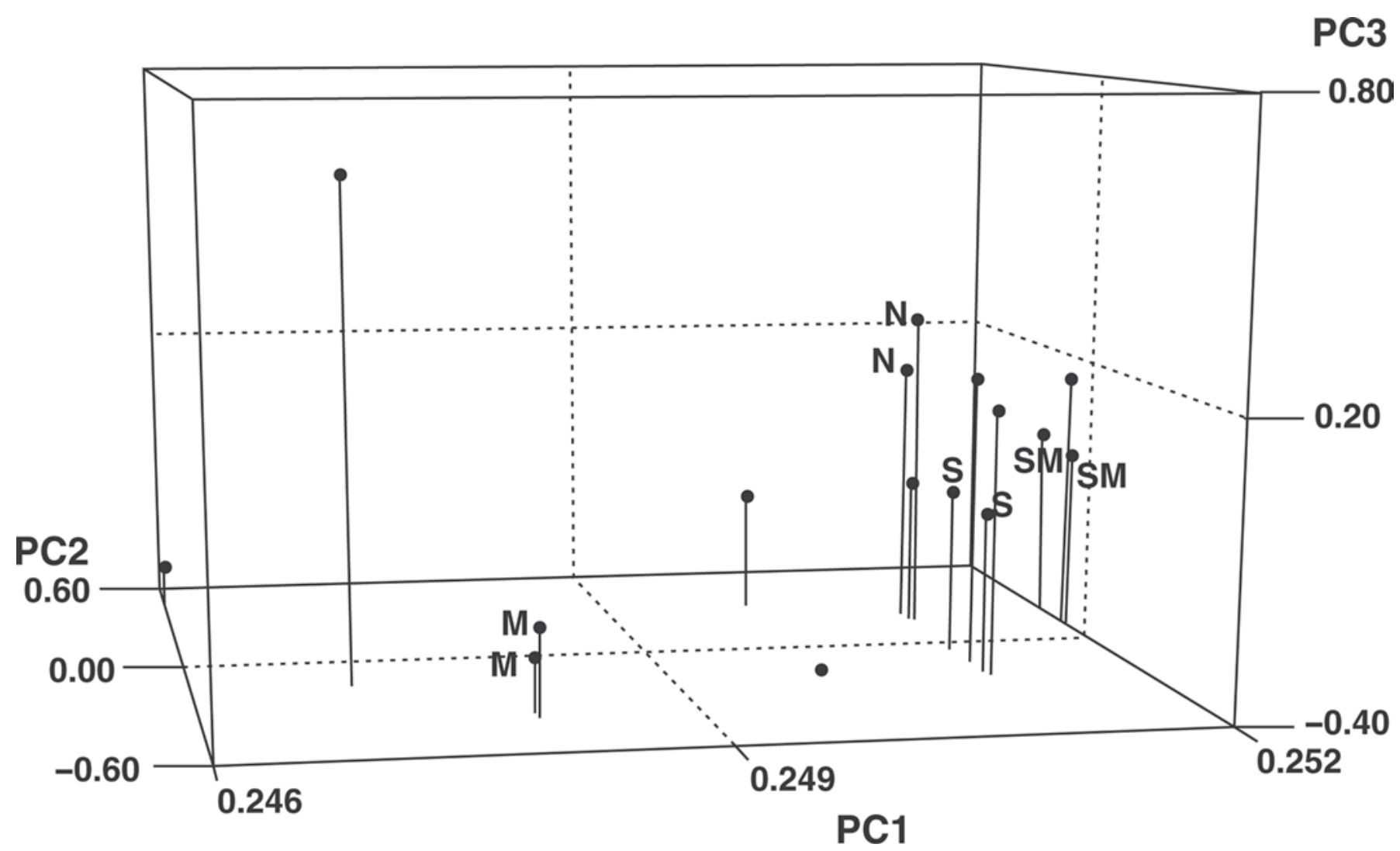

Figure 1. Selection of cows by milk fat response to different dietary treatments, based on cluster analysis. The groups identified by cluster analysis first were named based on their milk fat response shown in Table 2. Response groups include cows affected by starch fermentability (S), monensin (M; Rumensin 80, Elanco Animal Health, Greenfield, IN), or both (SM), and cows unaffected (N). After assignment of the 4 clusters, the clusters were visualized via principal component analysis using the first 3 principal components (PC1, PC2, PC3). 
with ARISA were somewhat higher than the number of visually distinguishable bands reportedly observed by gel-based ribsomal intergenic spacer analysis (Larue et al., 2005) or denaturing gradient gel electrophoresis (Sadet et al., 2007), alternative community fingerprinting techniques that are used in other ruminal bacterial population studies. Presumably, the higher number of AL revealed by ARISA reflects the higher resolution of capillary electrophoresis and the greater sensitivity of detection of the fluorescently labeled PCR products.

Figure 2 displays the ordination biplot from correspondence analysis of the ARISA data for the 4 pairs of cows that were grouped on the basis of different milk fat responses with dietary treatment. Each individual symbol in the figure represents the entire bacterial community from a single sample from an individual cow collected on a single sampling day. The proximity of one individual symbol to another is an indication of the overall similarity of the 2 samples with respect to the amount of an individual AL present, calculated across all AL in the sample. For each of the pairs of cows, the ruminal BCC broke out neatly into separate groups (i.e., the points in the ordination plot for one cow did not overlap with those of the other), indicating that overall the BCC was characteristic of individual animals. Within each cow-dietary treatment combination, coordinates for the solid and liquid fractions were closely spaced, suggesting relatively little difference in the BCC between the 2 phases. Figure 2 also reveals that samples collected on successive days for each cowdiet-phase combination displayed highly similar BCC, indicating both the stability of the populations at the 6-h postfeeding time after approximately 4 wk of dietary adaptation within each period and the reproducibility of the sample preparation and ARISA methods. This observation is consistent with the finding that sampling day within period was not significant in the full statistical model used to analyze individual AL.

Figure 2 shows that there were larger changes in BCC (greater distances between different numerals in the ordination biplot) following dietary shifts for cows in the S- and M-responsive groups than for cows in the SM- and nonresponsive groups. This was confirmed by higher ANOSIM R-values (indicating greater differences in BCC across the 188 AL examined) for comparisons between pairs of dietary treatments within cows (Table 4); numerous R-values of unity (the theoretical maximum) reflect the fact that ranking of samples within comparison groups can provide high $\mathrm{R}$-values when sample numbers are small (e.g., 3 samples for each of 2 diets within a single cow). In both S- and M-responsive cows, large changes in BCC were noted in cases where a dietary shift resulted in a change in milk fat production: SFS $\rightarrow$ RFS (symbols 1 and 2 in Figure 2) for S- responsive cows and RFS $\rightarrow$ RFS/Mon (symbols 2 and 3 in Figure 2) for M-responsive cows. However, numerous cases were observed in which large changes in BCC occurred with dietary shifts that did not yield changes in milk fat status, indicating that substantial changes in BCC with dietary shifts are the norm and that only some of these result in MFD. In SM-responsive cows, the shift in BCC was relatively modest across diets, indicating graded changes in the population in response to sequential exposure to highly fermentable starch, to monensin, and to monensin withdrawal. Nonresponsive cows also showed only small changes in BCC. For almost all individual cow-dietary treatment combinations, ANOSIM R-values were lower for the solids-associated bacterial community than liquid-associated bacterial community (Table 4), indicating that the former has greater overall stability than does the latter.

For all 3 groups that displayed a milk fat response to diet (S-, M-, and SM-responsive cows), monensin withdrawal did not fully restore the $\mathrm{BCC}$ to its original structure before monensin feeding (compare symbols 2 and 4 for each cow in Figure 2). Comparison within individual cows for experimental periods 2 (RFS diet) and 4 (RFS/Post diet) revealed that BCC generally did not reassemble to the same composition upon monensin removal (compare symbols 2 and 4 for each cow in Figure 2). This effect was particularly dramatic in M-responsive cows and is consistent with the continued decline in milk fat percentage observed even after monensin withdrawal (Table 2). However, the continued change in BCC upon monensin withdrawal was observed even in cows that did not display strong milk fat responses and whose $\mathrm{BCC}$ were only modestly altered by monensin.

Vectors for milk fat percentage, $\mathrm{pH}$, and $\mathrm{A}: \mathrm{P}$ showed relatively similar directionalities (indicating strongly positive relationships among these parameters) and stronger alignments along the first correspondence (horizontal) axis (i.e., the one accounting for the greatest variation in BCC). Total ruminal VFA concentration was also aligned with the horizontal axis but displayed the opposite directionality, suggesting a negative relationship with milk fat percentage, $\mathrm{pH}$, and A:P.

\section{Shifts in Populations of Individual AL}

The data matrix containing 188 different AL, based on the length of the separated amplicons, was examined to identify individual AL whose population tracked with milk fat response.

One AL (here designated AL246) whose PCR AL measured $246 \mathrm{bp}$ appeared to be strongly associated with MFD. When including data from all 4 dietary treatment periods, including the SFS diet, in the analy- 
sis, ARISA peak area was not significantly related to fat response group. However, there was a strong $(P<$ $0.001)$ fat group by dietary treatment period interaction: under conditions when milk fat levels were 3.5 to $4 \%$ by volume (SFS diet for all cows, and all diets for the fat-nonresponsive cows), AL246 was near or below detectable limits of the ARISA assay (Figure 2). In cows that displayed MFD (the S-, M-, and SM-responsive groups), AL246 populations were usually greatly elevated on the RFS diets that resulted in MFD. The S- and M-responsive cows retained high levels of AL246 after monensin withdrawal, during which time milk fat levels did not recover. The SM-responsive cows, which partially recovered from MFD upon monensin withdrawal (Table 2), displayed AL246 levels closer
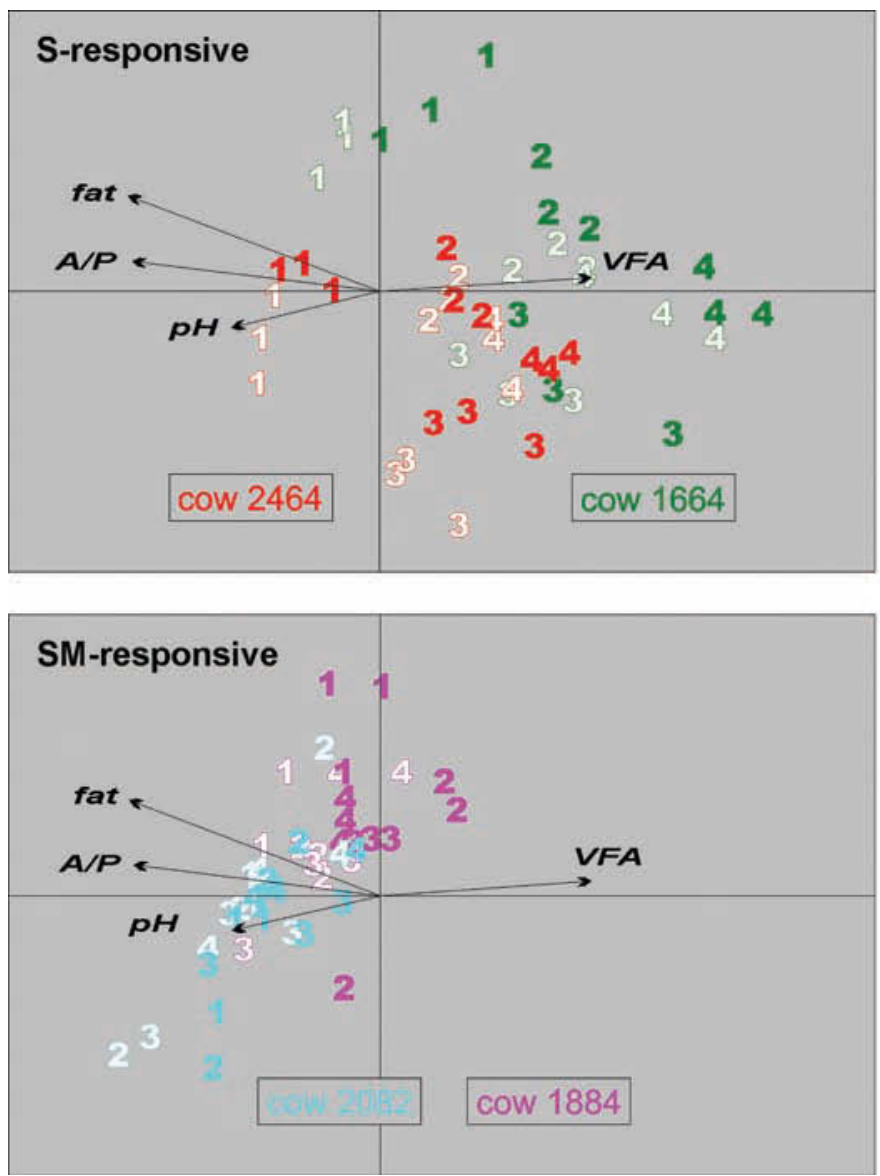

to those of the fat-nonresponsive cows upon monensin withdrawal. However, the relationship between AL246 and milk fat within period was not always clear-cut: Mresponsive cows displayed an increase in AL246 on the RFS diet in advance of significant MFD, and AL246 was barely detectable in SM-responsive cows on the RFS/Mon diet, during which their milk fat was at a minimum.

In addition to the several AL whose relative proportion increased in milk fat-responsive cows, $2 \mathrm{AL}$ $(\mathrm{AL}=383$ and $410 \mathrm{bp})$ were identified whose relative abundance tended to decrease in all of the cows that displayed MFD compared with the diet-nonresponsive cows. Both AL were numerically more abundant in the $\mathrm{S}-$ and M-responsive groups than in the SM-responsive
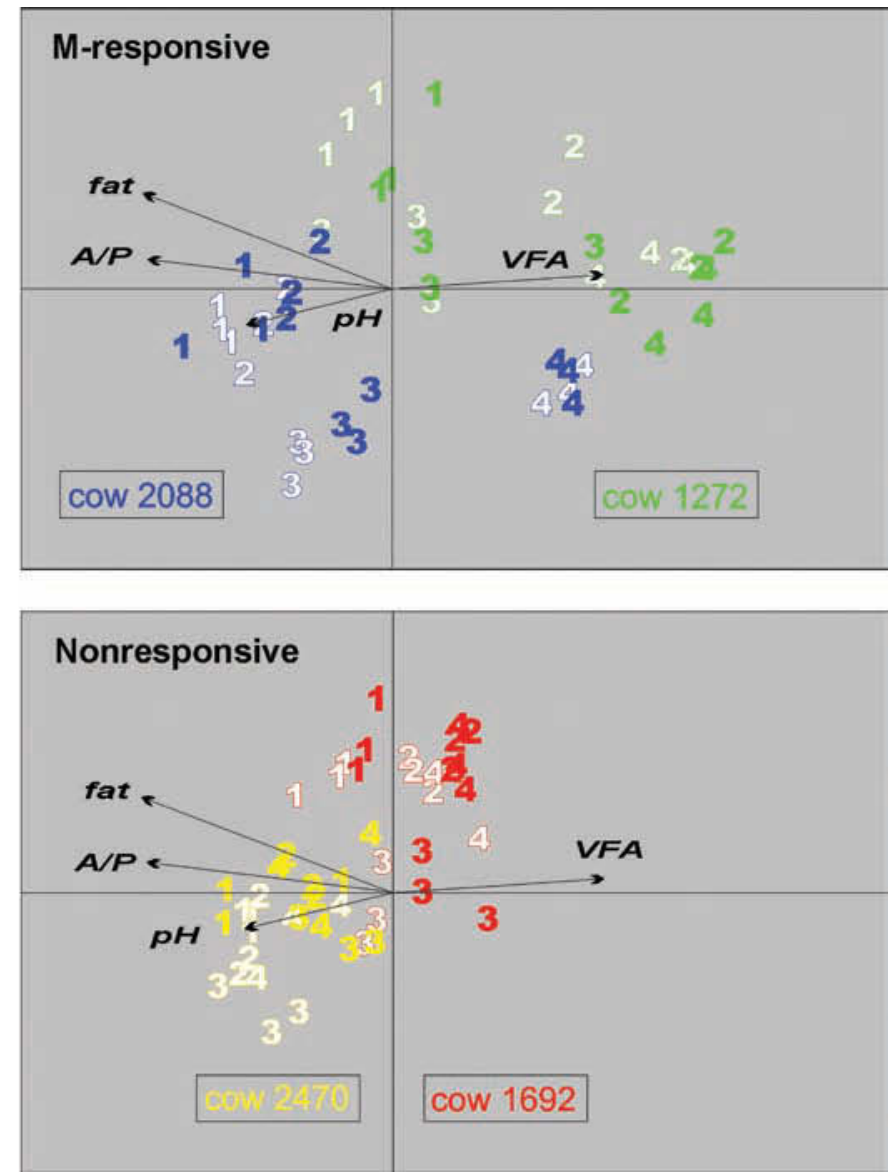

Figure 2. Correspondence analysis ordination biplot of ruminal bacterial community composition 6 h after feeding in 4 pairs of cows that showed differential milk fat response to dietary treatments. Response groups include cows affected by starch fermentability (S-responsive), monensin (M-responsive; Rumensin 80, Elanco Animal Health, Greenfield, IN), or both (SM-responsive), and cows unaffected (nonresponsive). Dietary treatments: SFS = slowly fermented starch diet $($ period 1$) ;$ RFS $=$ rapidly fermented starch diet $($ period 2$)$; RFS/Mon $=$ RFS diet amended with monensin (period 3); RFS/Post = RFS diet following monensin removal (period 4). The horizontal and vertical axes represent the first and second correspondence axes, respectively. All 4 biplots have the same scale but are separated here for clarity. Coordinate numerals indicate dietary treatment period. Filled numerals indicate particle-associated (solid phase) communities; open numerals indicate planktonic (liquid phase) communities. For each symbol type, the 3 replicate samples obtained on successive days are shown. Also shown are the vectors corresponding to milk fat percentage, ruminal $\mathrm{pH}$, ruminal acetate:propionate ratio, and ruminal total millimolar concentration of VFA. Vectors are identical in each panel because the automated ribosomal intergenic spacer analysis data were analyzed as a single set for all 8 cows. 
and nonresponsive groups and were affected by diet $(P=0.021$ and 0.025 for AL383 and AL410, respectively).

\section{DISCUSSION}

Rapidly fermented starch and monensin have both been reported to induce MFD in dairy cattle (Van Beukelen et al., 1984; Ramanzin et al., 1997; Oelker et al., 2009), and there is anecdotal evidence that cows fed diets high in rapidly fermented concentrates are more likely to display MFD upon monensin feeding (E. E. Thomas, Elanco Animal Health Inc., Greenfield, IN; personal communication). In this experiment, we examined the effect of rapidly fermented starch, with or without monensin, on milk fat production and on bacterial community composition. As noted above, because monensin has been shown to alter relative population sizes of at least several bacterial species (Weimer et al., 2008), experiments aimed at identifying ruminal bacterial population shifts could not use Latin square or switchback designs because the microbial response would be dependent on order of treatment. Consequently, the experimental design used here involved putting all 18 cows through the same sequence of diets (i.e., diets were confounded with treatment period), introducing the possibility that differences among the cows in stage of lactation may have contributed to observed fat production responses. Stanton et al. (1992), using a data set of over 3 million United States dairy cows, demonstrated that, after a nadir in milk fat percentage at approximately 30 DIM, cows regained milk fat percentage in a linear fashion at an average rate of approximately $0.0025 \% / \mathrm{d}$. The 8 cows selected by cluster analysis in our study differed by up to 55 DIM (Table 2 ); assuming a fat percentage regain of $0.0025 \% / \mathrm{d}$, this could have led to a difference in milk fat of up to $0.14 \%$ because of stage of lactation alone. However, this value is well under the observed 0.5 to $1.0 \%$ decrease in fat observed in the S-, M-, and SM-responsive cows, suggesting that the observed MFD was not solely an artifact of stage of lactation.

The data obtained here indicate that milk fat production in some cows is indeed sensitive to both rapidly fermented starch and monensin, whereas other cows appear to maintain milk fat production under the same conditions. The data also indicate that, at least in some cows, the effects of rapidly fermented starch and monensin in these high-starch diets are separable: some cows displayed MFD upon a switch to the RFS diet but did not respond to subsequent monensin feeding and withdrawal, whereas others did not display MFD upon switch to rapidly fermented starch but did display MFD upon simultaneous feeding of rapidly-fermented

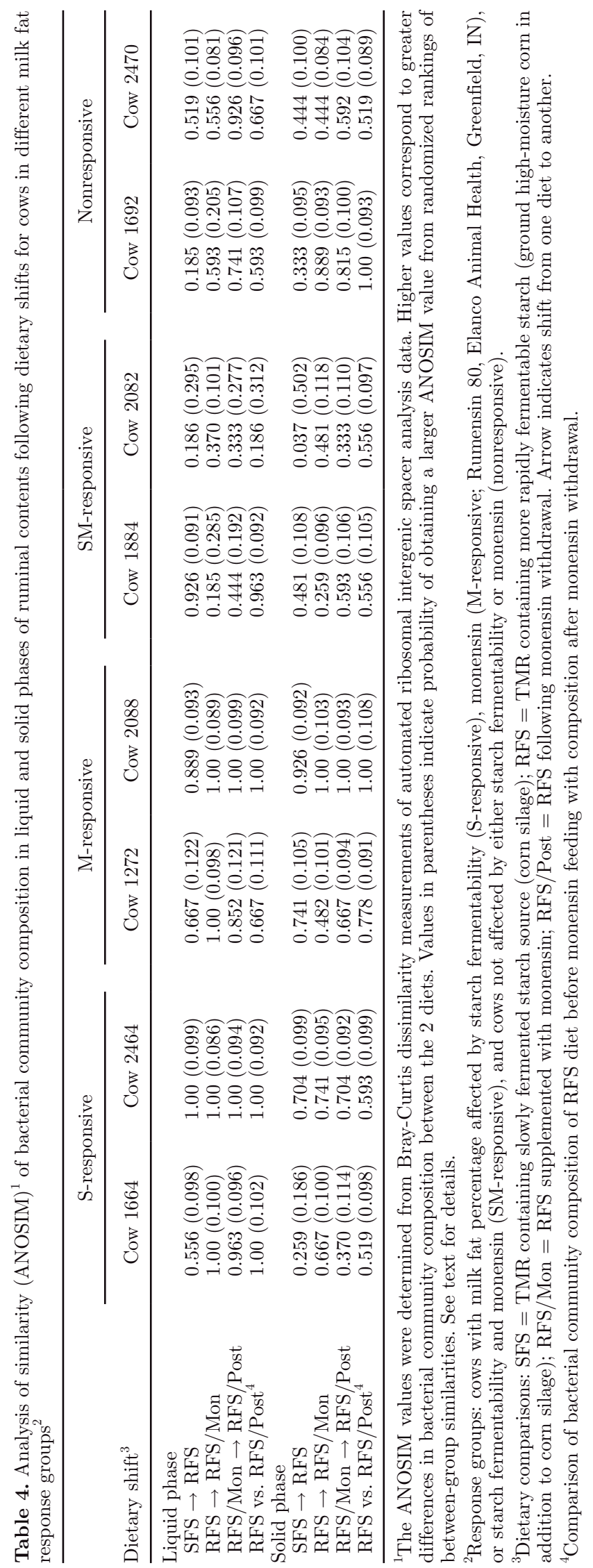


starch and monensin. In this latter group of cows, removal of monensin from the diet containing rapidly fermented starch did not result in recovery of milk fat levels within 4 wk of withdrawal (although these cows did recover fat production when returned to monensin for approximately 8 mo before a later companion study; Palmonari et al., 2010). Monensin-induced MFD has been reported to be more apparent or dramatic in cows at low production levels (Bradford and Allen, 2004), but we observed clear effects of monensin on milk fat levels in cows that showed good milk production (mean $\mathrm{FCM}=44.2 \mathrm{~kg} / \mathrm{d}$ on the SFS diet and $36 \mathrm{~kg} / \mathrm{d}$ across all diets).

There is little prior literature quantifying the effect of dietary treatments, including those involving monensin, on populations of specific microbial taxa in the rumen. Our previous work using qPCR to quantify specific taxa (Weimer et al., 2008) showed that, of 16 prokaryotic taxa examined, monensin affected the relative population sizes of only genus Prevotella and 3 species: Prevotella ruminicola, Megasphaera elsdenii, and the biohydrogenating species B. fibrisolvens. However, in that study, which employed only 2 cows, a specific association with MFD could not be drawn because milk fat responses to monensin were not observed. Moreover, the recent demonstration that the most commonly studied ruminal bacterial species represent only a small fraction of the total bacterial population in the rumen (Stevenson and Weimer, 2007; Wallace, 2008) indicated that further studies relating milk fat responses to dietary treatment would require both a larger number of animals and techniques that examined a broader segment of the ruminal microbial population. In the current study, we combined clustering of cows based on milk fat response with post hoc examination of bacterial populations in those cows, using a molecular ecology technique that examined the entire ruminal bacterial community (Welkie et al., 2009).

The molecular microbial ecological techniques (ARISA profiling and correspondence analysis) used in this study revealed that ruminal BCC, determined $6 \mathrm{~h}$ after daily feeding, attained considerable stability within each period by the time of the analysis. The bacterial community compositions at 26,27 , and $28 \mathrm{~d}$ after introduction of a new dietary treatment were closely spaced in ordination biplots of BCC as a whole (Figure $1)$, and sampling day was not significant $(P>0.30)$ for the relative ARISA peak areas of individual AL. This stabilization was observed in both the particleassociated (solid phase) and planktonic (liquid phase) populations, which also displayed substantial similarities to one another with respect to BCC in the ordination biplot. Despite the clear patterns of stabilization within cows, pairs of cows that displayed similar milk fat response to dietary treatments (revealed by cluster analysis) displayed substantial differences in BCC with essentially no overlap in the correspondence analysis profiles (Figure 2). This suggests that, although individual cows (both within and across milk fat response groups) shared a large number of bacterial AL, the relative abundances of the different AL varied substantially not only across response groups but even within individual cows that displayed similar milk fat responses to the dietary treatments. This was confirmed by a separate analysis demonstrating that the main effect of cow on individual AL was highly significant (generally $P<0.001$ for most taxa).

Although there were clear differences in BCC among cows, even in the same milk fat response group, there were also consistent shifts in BCC that were specifically related to dietary shifts. These changes in BCC were more dramatic in cows that displayed stronger milk fat responses (S- and M-responsive cows). Some of these diet-induced changes in BCC elicited MFD and some did not. As reported previously (Welkie et al., 2009), the solids-associated bacterial community appears to have greater overall stability than does the liquid-associated community. The observation that BCC changed in response to monensin withdrawal from the diet but did not recover the structure it had before monensin feeding (i.e., BCC differed in each cow in the RFS vs. RFS/Post experimental periods) is in accord with previous $\mathrm{qPCR}$ data that some bacterial taxa do not reach the same relative population sizes in the ruminal community following monensin feeding and withdrawal (Weimer et al., 2008). This observation indicates that, for monensin and other agents known to have effects on the microbial populations, prior history with the agent, including order of experimental treatments, can affect experimental outcomes. This should limit the use of some experimental designs (e.g., Latin-square or switchback designs) for certain microbiological studies.

Although Boeckaert et al. (2008) have recently shown that trans- $\mathrm{C}_{18: 1}$ fatty acid levels in the rumen are associated with changes in the relative proportions of individual Butyrivibrio strains, our study and the companion study of Palmonari et al. (2010) are the first, to our knowledge, in which a specific dairy production response (MFD) has been associated with a quantifiable shift in BCC as a whole. The fact that some, but not all, shifts in BCC yielded milk fat responses suggests that the specific combinations of taxa may be required to elicit MFD. Thus, targeted control of BCC, currently well beyond our capabilities, may one day afford a means for modulating milk composition. A first step in such targeted control will be identification of the taxa involved in MFD. The ARISA method has been widely used in microbial ecological studies to monitor shifts 


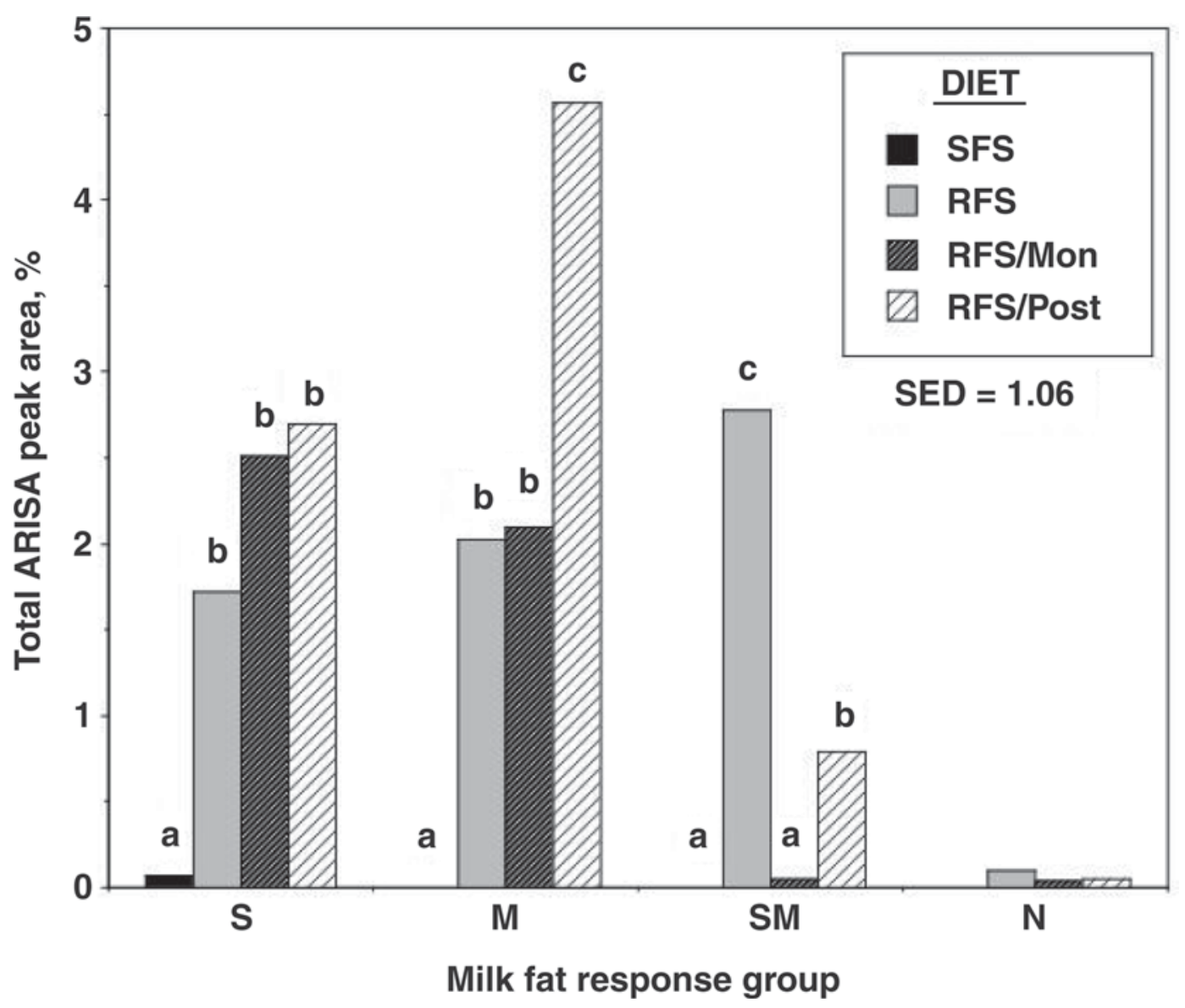

Figure 3. Effect of diet on the percentage of total automated ribosomal intergenic spacer analysis (ARISA) peak area contributed by AL246 (amplicon length measuring $246 \mathrm{bp}$ ) in cows grouped by their milk fat response to dietary treatments. Response groups include cows affected by starch fermentability (S), monensin (M; Rumensin 80, Elanco Animal Health, Greenfield, IN), or both (SM), and cows unaffected (N). Dietary treatments: SFS = slowly fermented starch diet (period 1); RFS = rapidly fermented starch diet (period 2); RFS/Mon = RFS diet amended with monensin (period 3); RFS/Post = RFS diet following monensin removal (period 4). Data for individual response group-diet combinations were averaged across sampling day within period and across phase (solid and liquid) of ruminal contents. Letters (a, b, c) above bars within milk fat response group indicate differences among means $(P<0.10)$. Means within the diet-nonresponsive cows $($ group $\mathrm{N})$ did not differ.

in BCC in natural systems subjected or not subjected to various perturbations (Fisher et al., 2000; Giraffa and Neviani, 2001; Yannarell and Triplett, 2005). This method is useful for providing a snapshot of bacterial community composition and for quantifying individual AL represented in the ARISA profile. However, ARISA cannot be used directly to identify specific taxa because several taxa may share the same ITS size, and the ITS size of most bacterial species (including all uncultured species) is unknown (Fisher and Triplett, 1999). Thus, quantification of individual $\mathrm{AL}$ is not equivalent to quantification of a unique species (Felske and Osborn, 2005). Nevertheless, peak area data for specific AL obtained by ARISA can be used to tentatively suggest which species may be undergoing substantial changes in relative population size.

In particular, we observed that one AL (AL246) generally became elevated in the rumen in cows that displayed MFD relative to cows that did not display MFD. In a companion study (Palmonari et al., 2010), we identified the apparent monophyletic unit within AL246 (designated operational taxonomic unit 246) as a close phylogenetic relative of Megasphaera elsdenii, and showed via $\mathrm{qPCR}$ that the relative abundance of operational taxonomic unit 246 and M. elsdenii were highly correlated $(\mathrm{r}=+0.99)$ across cows and were elevated only in cows that displayed low levels of milk fat. Moreover, both M-responsive cows used in our companion study (Palmonari et al., 2010, conducted approximately 1 yr after this study and after the cows had been returned to a monensin-containing diet) regained higher levels of milk fat and had reduced populations of M. elsdenii. These data thus support earlier, culture-based studies that identified $M$. elsdenii (then called Peptostreptococcus elsdenii) as one of 6 species whose relative population sizes were significantly el- 
evated in cows that displayed MFD on low-roughage diets containing flaked corn (Latham et al., 1972). In the current study, although relative abundance of AL246 (estimated by ARISA peak area) appears to be related to milk fat levels, the results suggest that this bacterium, by itself, is not necessary for eliciting MFD because it was virtually absent in SM-responsive cows on the RFS/Mon diet, when milk fat was at its lowest (Figure 3). Neither is the taxon represented by AL246 sufficient, by itself, for eliciting MFD because AL246 levels became elevated in M-responsive cows on the SFS diet in advance of observed MFD (Figure 3).

The potential involvement of $M$. elsdenii in MFD is further complicated by uncertainty regarding its potential to produce t10,c12-CLA, a known substrate for biohydrogenation reactions that yield long-chain fatty acids known to regulate mammary lipogenesis (Bauman and Griinari, 2003). Kim et al. (2002) reported that, of 5 strains of this species tested, 2 strains (YJ-4 and T81) produce this isomer. In a more recent report, Maia et al. (2007) observed no production of this isomer in 2 strains (including a culture of strain T81 obtained from another source). However, production of this isomer by strain YJ-4 in vitro is known to be dependent on culture conditions (Kim et al., 2005). Full resolution of this disparity will require specific isolation of the taxon represented by AL246 or other M. elsdenii strains from MFD cows and characterization of their ability to produce t10,c12-CLA in vitro under environmental conditions similar to those found in the rumen.

Currently unidentified taxa within 2 AL (AL 383 and AL 410) displayed reduced relative abundance in cows that displayed MFD. In our companion study (Palmonari et al., 2010), AL 383 and AL 246 were simultaneously present in only $21 \%$ of 143 ruminal samples examined, and when simultaneously present displayed opposite abundances. Taxa represented by AL 383 or AL 410 may have a protective role in either preventing ruminal accumulation of long-chain fatty acids that can suppress mammary lipogenesis or in controlling the populations of $M$. elsdenii or other taxa that may negatively affect milk fat production. In light of this, future research should emphasize identification of these currently uncharacterized species as well as others whose populations showed changes with dietary treatment.

\section{CONCLUSIONS}

Cows differ considerably with respect to the effect of both starch source and monensin on milk fat production. In high-starch diets, the milk fat-depressing effects of rapidly fermented starch and monensin, when observed, can act individually or in tandem depending on the individual animal. Although bacterial community composition of the rumen, as determined by ARISA and correspondence analysis, differed even between individual cows that responded similarly to monensin or to starch source, clear shifts in community composition were observed that coincided with the milk fat response; this indicated a direct association between dairy production in the host animal and its ruminal bacterial community composition. In line with the observed population shifts, the relative abundances of several AL showed clear differences among cows that displayed differences in susceptibility to MFD. The species represented by these AL may be important determinants of milk fat production in dairy cows.

\section{ACKNOWLEDGMENTS}

This research was supported by a Trust Fund Agreement between the USDA-Agricultural Research Service (Washington, DC) and Elanco Animal Health Inc. (Greenfield, IN). We thank E. E. Thomas, Elanco Animal Health, for providing monensin and for valuable discussions on its use and its effects under production conditions. We thank J. Meronek, M. Hintz, and the US Dairy Forage Research Center (USDFRC; Madison, WI) barn crew for assistance with the animal trial; M. Maroney and R. Stauffacher (University of WisconsinMadison) for veterinary surgery; and C. L. Odt (USDFRC) for technical assistance. We also thank M. B. Hall and J. B. Russell (USDFRC); L. Armentano, R. J. Newton, and A. Shade (University of WisconsinMadison); and A. Palmonari (Universiti di Bologna, Italy) for helpful discussions.

\section{REFERENCES}

Bauman, D. E., and J. M. Griinari. 2003. Nutritional regulation of milk fat synthesis. Annu. Rev. Nutr. 23:203-227.

Boeckaert, C., B. Vlaeminck, V. Fievez, L. Maignien, J. Dijkstra, and N. Boon. 2008. Accumulation of trans $-\mathrm{C}_{18: 1}$ fatty acids in the rumen after dietary algal supplementation is associated with changes in the Butyrivibrio community. Appl. Environ. Microbiol. 74:6923-6930.

Bradford, B. J., and M. S. Allen. 2004. Milk fat responses to a change in diet fermentability vary by production level in dairy cattle. J. Dairy Sci. 87:3800-3807.

Cardinale, M., L. Brusetti, P. Quatrini, S. Borin, A. M. Puglia, A. Rizzi, E. Zanardini, C. Sorlini, C. Corselli, and D. Daffonchio. 2004. Comparison of different primer sets for use in automated ribosomal intergenic spacer analysis of complex bacterial communities. Appl. Environ. Microbiol. 70:6147-6156.

Clarke, K. R. 1993. Non-parametric multivariate analyses of changes in community structure. Aust. J. Ecol. 18:117-143.

Danovaro, R., G. M. Luna, A. Dell'Anno, and B. Pietrangeli. 2006. Comparison of two fingerprinting techniques, terminal restriction fragment length polymorphism and automated ribosomal intergenic spacer analysis, for determination of bacterial diversity in aquatic environments. Appl. Environ. Microbiol. 72:5982-5989.

Emery, R. S. 1988. Milk fat depression and the influence of diet on milk composition. Vet. Clin. North Am. Food Anim. Pract. 4:289-305. 
Felske, A., and A. M. Osborn. 2005. DNA fingerprinting of microbial communities. Pages 65-96 in Molecular Microbial Ecology. A. M. Osborn and C. J. Smith, ed. Taylor and Francis, New York, NY.

Fisher, M. M., M. J. Klug, G. M. Lauster, R. J. Newton, and E. W. Triplett. 2000. Effects of resources and trophic interactions on freshwater bacterioplankton diversity. Microb. Ecol. 40:125-138.

Fisher, M. M., and E. W. Triplett. 1999. Automated approach for ribosomal intergenic spacer analysis of microbial diversity and its application to freshwater bacterial communities. Appl. Environ. Microbiol. 63:4630-4636.

Forster, R. J., J. Gong, and R. M. Teather. 1997. Group-specific 16S rRNA hybridization probes for determinative and community structure studies of Butyrivibrio fibrisolvens in the rumen. Appl. Environ. Microbiol. 63:1256-1260.

Giraffa, G., and E. Neviani. 2001. DNA-based, culture-independent strategies for evaluating microbial communities in food-associated ecosystems. Int. J. Food Microbiol. 67:19-34.

Hall, M. B. 2009. Analysis of starch, including maltooligosaccharides, in animal feeds: A comparison of methods and a recommended method for AOAC collaborative study. J. AOAC Int. 92:42-49.

Harfoot, C. G., and G. P. Hazlewood. 1988. Lipid metabolism in the rumen. Pages 285-321 in The Rumen Microbial Ecosystem. P. N. Hobson, ed. Elsevier Applied Science, New York, NY.

Kara, E., and A. Shade. 2009. Temporal dynamics of South End Tidal Creek (Sapelo Island, Georgia) bacterial communities. Appl. Environ. Microbiol. 75:1058-1064.

Kim, T. W., N. J. Choi, J. Hwangbo, J. T. Hsu, S. S. Lee, M. K. Song, I. J. Seo, and Y. J. Kim. 2005. Production of trans-10, cis-12 conjugated linoleic acid by Megasphaera elsdenii YJ-4: Physiological roles in the rumen. Asian-australas. J. Anim. Sci. 18:1425-1429.

Kim, Y. J., R. H. Liu, J. L. Rychlilk, and J. B. Russell. 2002. The enrichment of a ruminal bacterium (Megasphaera elsdenii YJ-4) that produces the trans-10, cis-12 isomer of conjugated linoleic acid. J. Appl. Microbiol. 92:976-982.

Larue, R., Z. T. Yu, V. A. Parisi, A. R. Egan, and M. Morrison. 2005. Novel microbial diversity adherent to plant biomass in the herbivore gastrointestinal tract, as revealed by ribosomal intergenic spacer analysis and rrs gene sequencing. Environ. Microbiol. $7: 530-543$.

Latham, M. J., J. E. Storrey, and M. E. Sharpe. 1972. Effect of lowroughage diets on the microflora and lipid metabolism in the rumen. Appl. Microbiol. 24:871-877.

Loisel, P., J. Harmand, O. Zemb, E. Latrille, C. Lobry, J. P. Delgenes, and J. J. Godon. 2006. Denaturing gradient electrophoresis (DGE) and single strand conformation polymorphism (SSCP) molecular fingerprintings revisited by simulation and used as a tool to measure microbial diversity. Environ. Microbiol. 8:720-731.

Ludwig, J. A., and J. F. Reynolds. 1988. Statistical Ecology. John Wiley and Sons, New York, NY.

Maia, M. R. G., L. C. Chaudhary, L. Figueres, and R. J. Wallace. 2007. Metabolism of polyunsaturated fatty acids and their toxicity to the microflora of the rumen. Ant. van Leeuwenhoek 91:303-314.

McCune, B., and J. B. Grace. 2002. Ecological Communities. MjM Software Design, Gleneden Beach, Oregon.

Mertens, D. R. 2002. Gravimetric determination of amylase-treated neutral detergent fiber in feeds with refluxing in beakers or crucibles: Collaborative study. J. AOAC Int. 85:1217-1240.

Nielsen, T. S., E. M. Straarup, M. Vestergaard, and K. Sejrsen. 2006. Effect of silage type and concentrate level on conjugated linoleic acids, trans-C18:1 isomers and fat content in milk from dairy cows. Reprod. Nutr. Dev. 46:699-712.

Oba, M., and M. S. Allen. 2003. Effects of corn grain conservation method on ruminal digestion kinetics for lactating dairy cows at two dietary starch concentrations. J. Dairy Sci. 86:184-194.

Oelker, E. R., C. Reveneau, and J. L. Firkins. 2009. Interaction of molasses and monensin in alfalfa hay- or corn silage-based diets on rumen fermentation, total tract digestibility, and milk production by Holstein cows. J. Dairy Sci. 92:270-285.

Owens, F. N., R. A. Zinn, and Y. K. Kim. 1986. Limits to starch digestion in the ruminant small intestine. J. Anim. Sci. 63:16341648

Palmonari, A., D. M. Stevenson, D. R. Mertens, and P. J. Weimer. 2010. $\mathrm{pH}$ dynamics and bacterial community composition in the rumen of lactating dairy cattle. J. Dairy Sci. 93:279-287.

Peterson, D. G., E. A. Matitashvili, and D. E. Bauman. 2003. Dietinduced milk fat depression in dairy cows results in increased trans-10, cis-12 CLA in milk fat and coordinate suppression of mRNA abundance for mammary enzymes involved in milk fat synthesis. J. Nutr. 133:3098-3102.

Ramanzin, M., L. Bailoni, S. Schiavon, and G. Bittante. 1997. Effect of monensin on milk production and efficiency of dairy cows fed two diets differing in forage to concentrate ratios. J. Dairy Sci. 80:1136-1142.

Rosenfeld, I. S., and S. B. Tove. 1971. Biohydrogenation of unsaturated fatty acids. J. Biol. Chem. 246:5025-5030.

Sadet, S., C. Martin, B. Meunier, and D. P. Morgavi. 2007. PCR-DGGE analysis reveals a distinct diversity in the bacterial population attached to the rumen epithelium. Animal 1:939-944.

San Emeterio, F., R. B. Reis, W. E. Campos, and L. D. Satter. 2000. Effect of coarse or fine grinding on utilization of dry or ensiled corn by lactating dairy cows. J. Dairy Sci. 83:2839-2848.

SAS Institute. 1998. SAS User's Guide. Version 7. SAS Institute Inc., Cary, NC.

Stanton, T. L., L. R. Jones, R. W. Everett, and S. D. Kachman. 1992. Estimating milk, fat, and protein lactation curves with a test day model. J. Dairy Sci. 75:1691-1700.

Stevenson, D. M., and P. J. Weimer. 2007. Dominance of Prevotella and low abundance of classical ruminal bacterial species in the bovine rumen revealed by relative quantification real-time PCR. Appl. Microbiol. Biotechnol. 75:165-174.

Tajima, K., R. I. Aminov, T. Nagamine, K. Ogata, M. Nakamura, A. Matsui, and Y. Benno. 1999. Rumen bacterial diversity as determined by sequence analysis of $16 \mathrm{~S}$ rDNA libraries. FEMS Microbiol. Ecol. 29:159-169.

Tajima, K., A. Shozo, K. Ogata, T. Nagamine, H. Matsui, M. Nakamura, R. Aminov, and Y. Benno. 2000. Rumen bacterial community transition during adaptation to a high-grain diet. Anaerobe 6:273-284.

Van Beukelen, P., A. F. V. Van Lingen, M. E. Peeters, T. Wensing, and H. Breukink. 1984. Effects of monensin in the ration on milk fat production and some rumen metabolites in cows during early and midlactation. Zentralbl. Vet. Reihe A. 31:350-360.

Wallace, R. J. 2008. Gut microbiology - Broad genetic diversity, yet specific metabolic niches. Animal 2:661-668.

Weimer, P. J., Y. Shi, and C. L. Odt. 1991. A segmented gas/liquid delivery system for continuous culture of microorganisms on solid substrates, and its use for growth of Ruminococcus flavefaciens on cellulose. Appl. Microbiol. Biotechnol. 36:178-183.

Weimer, P. J., D. M. Stevenson, D. R. Mertens, and E. E. Thomas. 2008. Effect of monensin feeding and withdrawal on populations of individual bacterial species in the rumen of lactating dairy cows fed high-starch rations. Appl. Microbiol. Biotechnol. 80:135-145.

Welkie, D. G., D. M. Stevenson, and P. J. Weimer. 2009. ARISA analysis of ruminal bacterial community dynamics in lactating dairy cows during the feeding cycle. Anaerobe doi:10.1016/j. anaerobe.2009.07.002.

Whitford, M. F., R. J. Forster, C. E. Beard, J. Gong, and R. M. Teather. 1998. Phylogenetic analysis of rumen bacteria by comparative sequence analysis of cloned 16S rRNA genes. Anaerobe 4:153163.

Yannarell, A. C., and E. W. Triplett. 2005. Geographic and environmental sources of variation in lake bacterial community composition. Appl. Environ. Microbiol. 71:227-239. 